\title{
Assessment of Training Quality Management According to "Total Quality Management" Model at Vienam National University, Hanoi - International School
}

\author{
Nguyen Phan Quang*, Vu Ngoc Tu \\ VNU International School, Building G7-G8, 144 Xuan Thuy, Cau Giay, Hanoi, Vietnam
}

Received 22 April 2017

Revised 12 June 2017; Accepted 28 June 2017

\begin{abstract}
The application of the "Total Quality Management" model (TQM) in quality management and accreditation has been adopted by many countries in the world, but in Vietnam it is still quite new. To investigate and study the applicability and evaluation of general management and training quality management in particular according to TQM in order to propose practical suggestions to the International School, Vietnam National University, Hanoi (VNU), the authors have conducted a survey of 168 students ( 25 first-year students, 53 second-year students, 51 thirdyear students, 39 fourth-year students); 23 teaching and management staff. The results indicate that the current training quality management is evaluated to be average by students and quite good by teaching and management staff. All the students and staff argue that the implementation of training quality management according to TQM criteria is feasible.
\end{abstract}

Keywords: Quality management, joint training, total quality management (TQM).

\section{Introduction}

Over the last years, training quality management $(\mathrm{QM})$ has been a hot issue in all higher education institutions (HEI) in Vietnam as training quality and efficiency are still low. That has been confirmed by Vallely (2008) who states that Vietnam does not have even a single university of recognized quality and paid due attention to by the Vietnamese government, education leaders as well as educators and scientists. Hence, there have been a number of scientific conferences/workshops and researches

\footnotetext{
*Corresponding author. Tel.: 84-986222359.

Email: quangnp@isvnu.vn

https://doi.org/10.25073/2588-1116/vnupam.4095
}

on QM such as: "Quality assurance in Vietnam's in Vietnam's higher education" coorganized by Vietnam's Ministry of Education and Training and UNESCO in April, 2000, "Education quality and living skills" organized by UNESCO, Asia-Pacific Region in September, 2003, "Higher education reform and international integration" organized by National Council on Education in June, 2004, "Education quality and Teacher training" organized by Faculty of Education, Vietnam National University, Hanoi (VNU) in October, 2004 and "Education internationalization" organized by VNU International School in 2015 just to name a few. In his research "Quality management in higher education", Pham Thanh Nghi (2000) reviewed different schools of education quality 
and pointed out criteria, standards, assessment process (internal and external) of higher education quality assurance. That has been followed by other researchers like Tran Khanh Duc (2003, 2009), Nguyen Huu Chau (2006) and Bui Minh Hien et al...All those conferences/workshops and researches have focused on the existing situations of quality management/assurance in the world in general and Vietnam in particular and pointed out problems as well as put forward solutions for improving the training and research quality in Vietnam. Along those lines, this paper looks at quality management, total quality management and the applicability of training quality management according to "total quality management" model in VNU International School with the hope that it will make a modest contribution to further improving the training quality in VNU International School.

\section{Literature review}

Quality management and total quality management (TQM) are defined differently by different researchers. However, the authors just review some of them which serve as theoretical backgrounds for this study.

\subsection{Quality management}

Feigenbaum (1991) states that quality management $(\mathrm{QM})$ is a unified system of effective operation of the various units within an organization responsible for implementing quality parameters, maintaining and enhancing the existing quality level. Robertson (1971) argues that product quality management is defined as a management system that aims at developing a program of coordinated efforts by different units to maintain and enhance the quality in the designing and production process so as to ensure the most effective production, while satisfying all the requirements of consumers. QM is also defined as ensuring that an organization, product or service is consistent [1-3]. QM is said to have four components: quality planning, quality assurance, quality control and quality improvements. QM focuses on product and service quality and on the means to achieve it. QM, hence, applies quality assurance and control process as well as product to achieve more consistent quality. Or QM is the conformance to requirements, not "goodness" and the system of achieving quality is prevention, not appraisal. It is also stated that the primary focus of QM is to satisfy customer requirements and to try to exceed their expectation.

QM may also be defined as managing the entire organization in such a way that it excels on all dimensions of products and services important to the customer. Or it may be defined as the integration of all functions and processes within an organization in order to achieve continuous improvement of the quality of goods and services.

In short, it can be said that quality management is the activities that aim to direct, organize, use resources, and coordinate the actions of a group or organization to achieve the desired quality and satisfy customers.

\subsection{Training quality management}

Training quality management in higher education institutions must cover the fields according to their common functions and activities to ensure necessary conditions for such functional areas to effectively operate. Higher education institutions can be viewed in eight areas of quality management: training management, scientific research management, community service management, staff management as well as management of training support services, asset management, management and administration (Piper, 1993).

Training quality management which covers all areas in any higher education institutions is composed of a complex management system with the participation and interaction of many components from training input to training output. The performance quality of each 
component influences the overall quality of the whole process.

Thus, to analyze the components of the training quality management, according to Piper (1993), is to examine the issues related to the provision of training services to students, assess the effects of management activities and the process of quality assurance.

\subsection{Total Quality Management (TQM)}

According to Bergman and Klefsjo (2003), TQM is an ongoing effort to accomplish and excel beyond the customer's expectations by making costs lower, by continuous improvements, by focusing on the process with the participation and commitment of everyone in an organization.

Although there are many different concepts of TQM, it is commonly stated that TQM is based on quality-focused management, through the development of a quality control system that verifies the control of all stages of the implementation process, in which due attention is paid to quality in all activities. It is the understanding, commitment, cooperation of all members of the organization to provide customers with what they need, when they need it and in the way they need it, satisfy and exceed their expectations $[4,5]$. TQM is said to consist of 5 core elements as follows: (1) focus on the customer; (2) making decisions based on reality; (3) focus on the process; (4) continuous improvements and (5) commitment of everyone [5]. These core elements mentioned above are closely related to one another, especially to the role of the customers. TQM is also defined as meeting the customer requirements, doing things right the first time, freedom from failure, consistency, continuous improvement, quality in everything we do [6]. In that connection, TQM is said to be the highest level if compared with other levels in quality management. The hierarchy of the relationships in quality management can be exemplified in Sallis's hierarchy of the quality concept in Chart 1 .

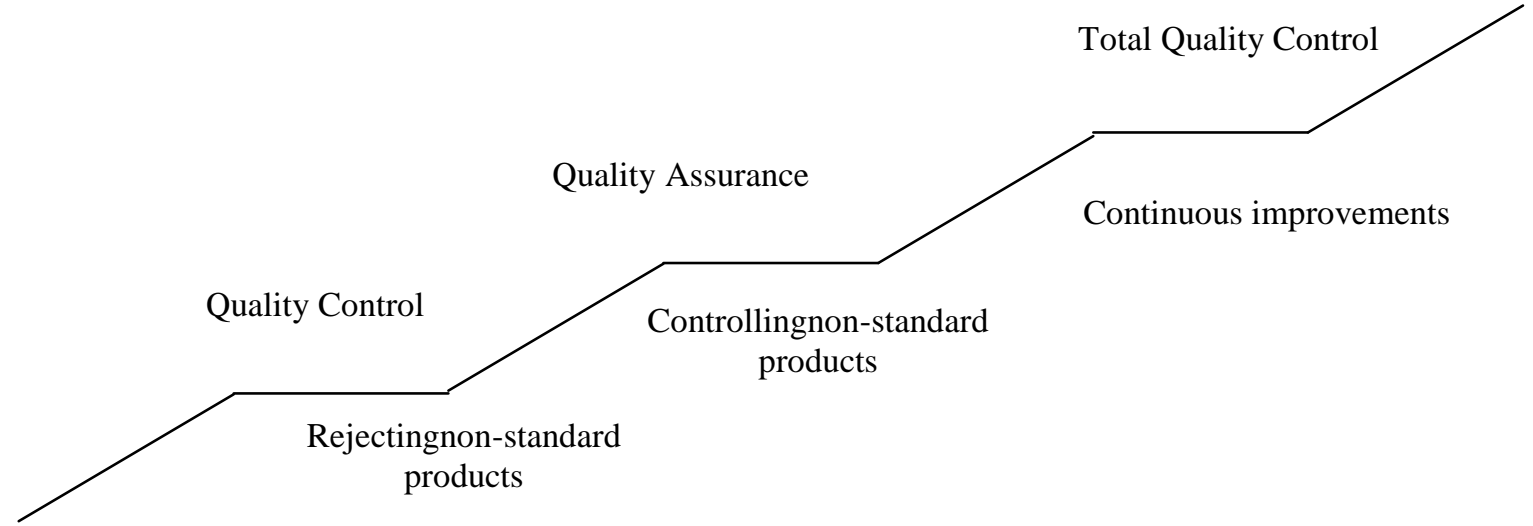

Chart 1. Quality management levels.

(Source: Sallis, 1993)

On the basis of those working definitions, the authors have conducted their research by collecting data from questionnaire and interviews and have recorded the following results.

\section{Research results}

On the basis of the previous studies of training quality management, the questionnaire was designed with 29 questions (items) divided into 8 areas: (i) consultancy and orientation, (ii) services for students, (iii) school's management, 
(iv) inside environment and resources, (vi) learning and teaching activities, (vi) issues relating to students, (vii) issues relating to teaching and learning staff and (viii) relation between school and community. To analyze the interviewees' assessment of the school's training quality management, Likert scale was used from 1 to 5 with level 1 being the lowest and level 5 the highest.

For the purpose of assessing the awareness of each of the criteria for the study, the respondents (students and teaching and management staff) were asked to indicate their level of agreement with each of the given items
The questionnaire was then delivered to 168 students and 23 teaching and management staff, 200 with valid information (with complete information) were collected and analyzed.

\subsection{Reliability of the questionnaire}

The results of Cronbach's Alpha analysis show that the questionnaire has a coefficient of reliability of 0.928 , which is a high value, indicating that the toolkit is highly reliable. That can be exemplified in Table 1 .

Table 1. Confidence coefficient of the scale (students' data)

Reliability Statistics

\begin{tabular}{ccc}
\hline Cronbach's Alpha & $\begin{array}{c}\text { Cronbach's Alpha Based on } \\
\text { Standardized Items }\end{array}$ & N of Items \\
\hline 0.928 & 0.929 & 29 \\
\hline
\end{tabular}

Similarly, the analysis of the data in the questionnaire for students, the results of Cronbach's Alpha analysis of the teaching staff show that the questionnaire has a coefficient of confidence of 0.924 , which is a relatively good value. The toolkit is highly reliable, from the perspective of the teaching staff. This can be illustrated in Table 2.

Table 2. Confidence coefficient of the scale (teaching and management staff's data)

Reliability Statistics

\begin{tabular}{ccc}
\hline Cronbach's Alpha & $\begin{array}{c}\text { Cronbach's Alpha Based on } \\
\text { Standardized Items }\end{array}$ & N of Items \\
\hline .914 & .920 & 29 \\
\hline
\end{tabular}

\subsection{Students' assessment of the training management quality}

In the case of this study, it can be understood that the Likert scale applied only has the assessment levels from low to high. If looking at the difficulty distribution of questions with respondents' ability calculated by using CONQUEST, one can see that the respondents evaluating whether the training quality management is high or low. Accordingly, the distribution of the degree of difficulty with high level of competence means that the quality is assessed well, whereas the degree of difficulty with low level of competence means not good quality evaluation. Comparative results are shown in Chart 2: 


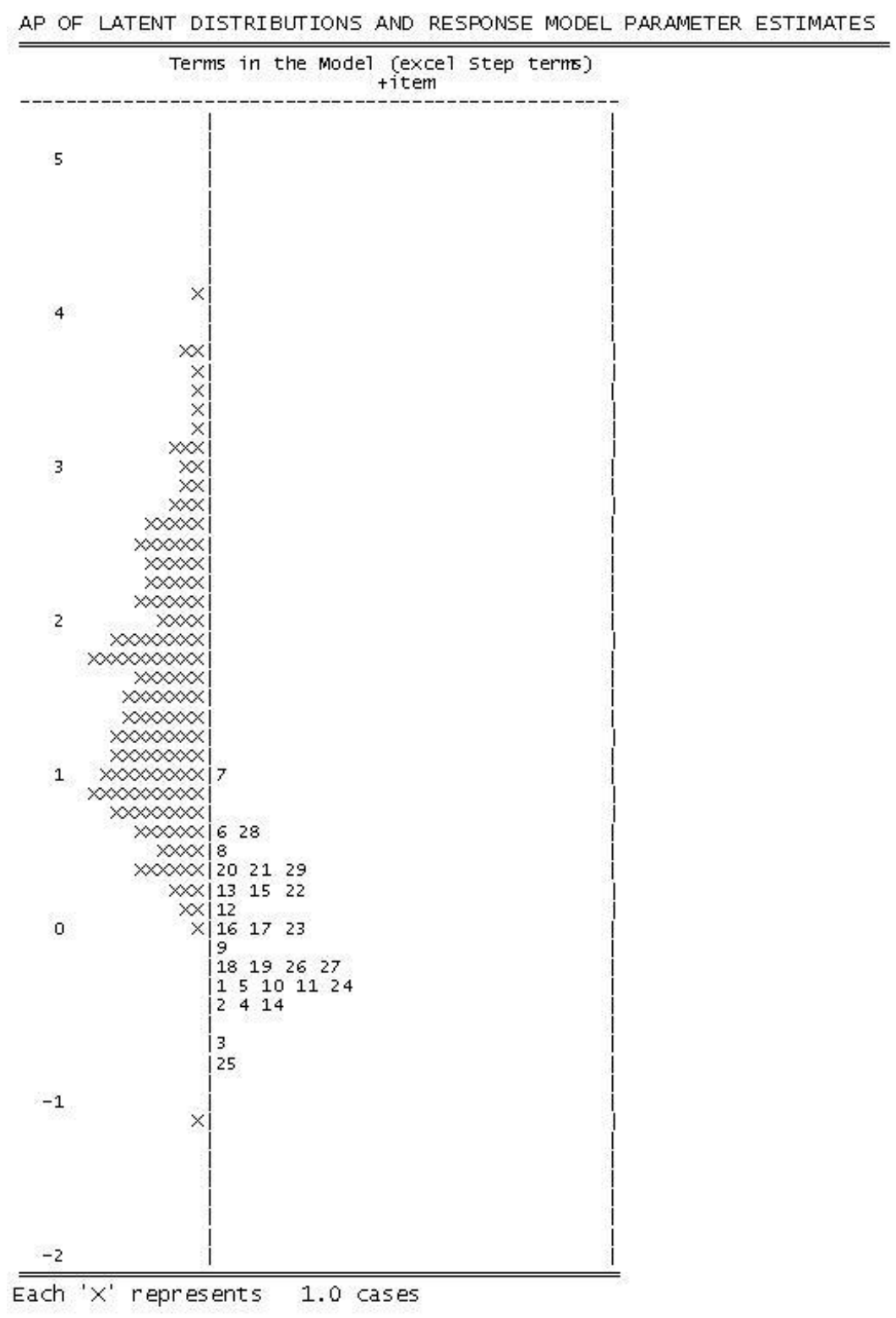

Chart 2. Distributing answers by rating levels.

According to the chart, the distribution of answers concentrates on the lower part of the low capacity, meaning that the respondents state that the Accounting, Analyzing and Auditing program is at average and good levels.

However, looking at the detailed variable chart, which includes the level of students' assessment for each level in each criterion, the student's assessment of some of the criteria remains high, that is, there are still other levels such as level 5 of criterion 7 were highly appreciated by all students. This can be manifested in Chart 3. 


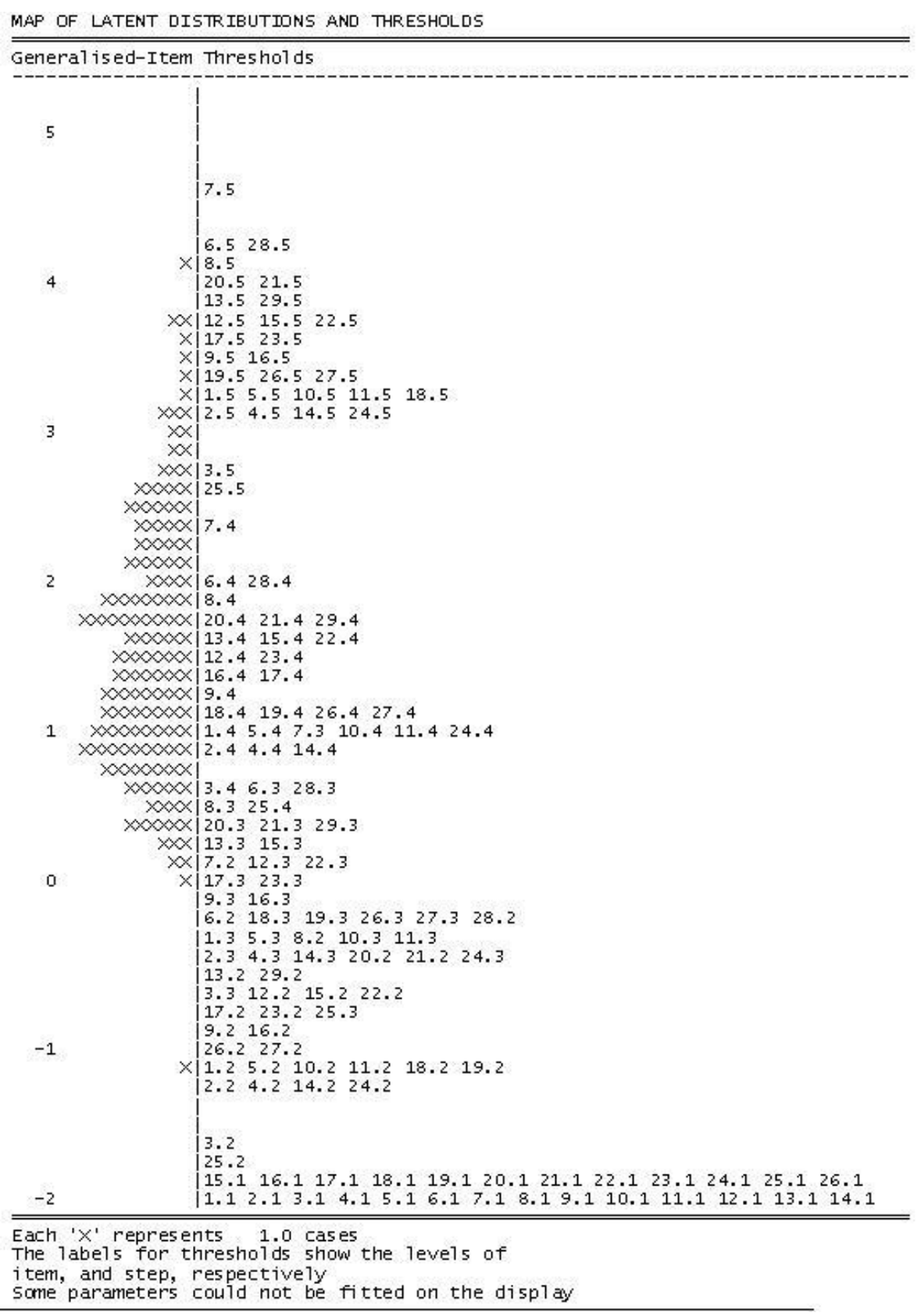

Chart 3. Detailed variable chart.

\subsection{Teaching and management staff's} assessment on training quality management

From the data collected and analyzed, it is correct to say that teaching staff 's evaluation of the training quality management mainly concentrates on levels $3,4,5$ of which level 4 is most popular. This can be seen in Chart 4 . 


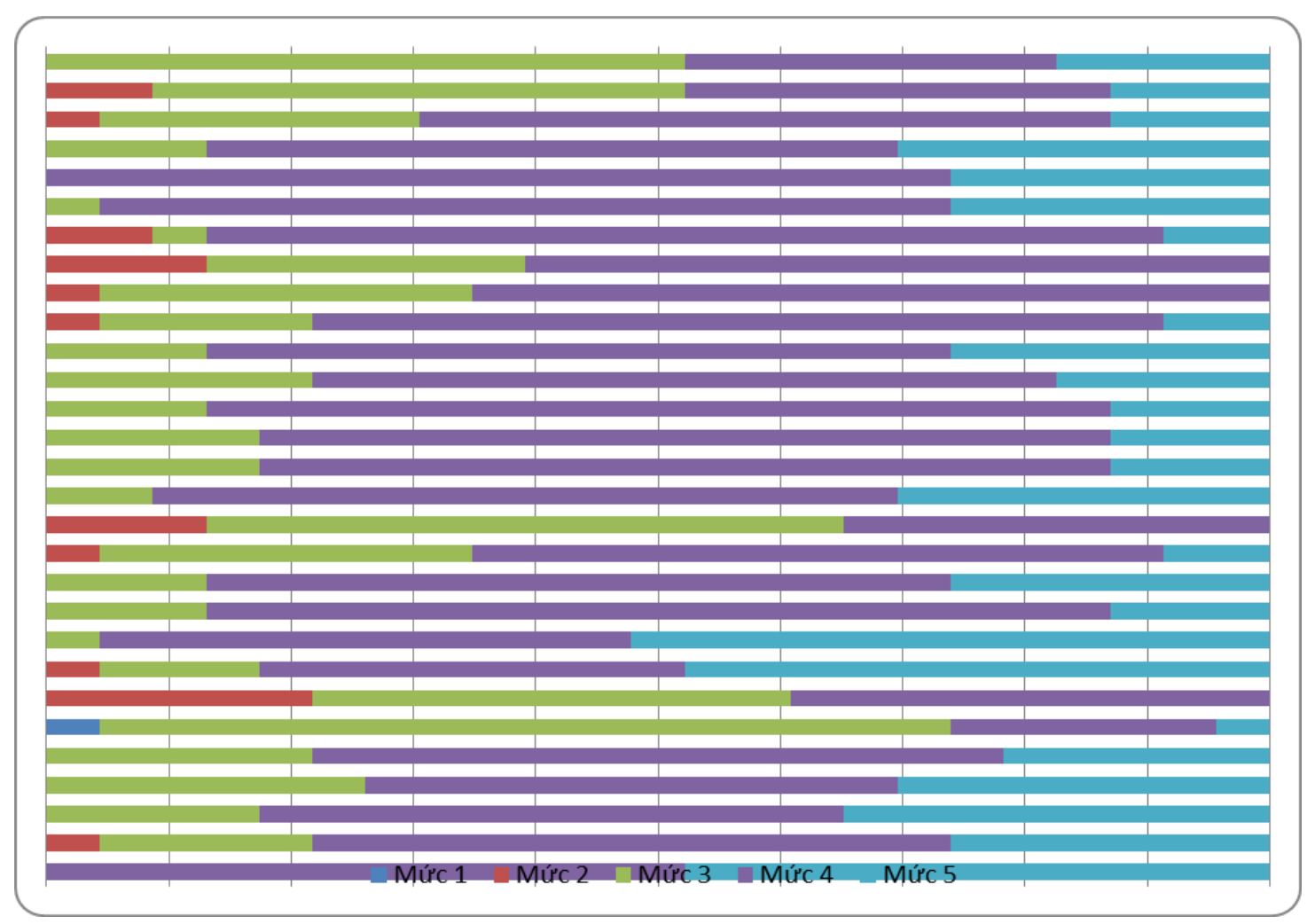

Chart 4. Teachers' ratings on training quality management.

Looking at the chart, one can see that the staff's evaluation of the training quality management is at a good level. Compared with the students' assessment, this result seems to be inconsistent, while the majority of students evaluate the training quality management at average and good levels but teaching staff hold that the training quality management is good and very good. The bad and very bad ratings rarely appear.

This can be explained by the objective and subjective reasons. The objective reason is that teaching staff are directly related and more deeply understand the process of the training quality management so the evaluation in some cases is more accurate. The subjective reason is that the teaching staff are directly involved in the implementation of the training quality management, so the self-assessment may sometimes bear the psychological factors. For the students, they are the "customers" of the higher education, the direct users of services (training management), then the centralized assessment may be more objective. But it can also be understood in such a way that the students have not approached and had a deep understanding of all the aspects of the training quality management. Therefore, the objective evaluation does not reflect the reality. This can be more clearly seen in Table 3 .

Table 3. Frequency response rate in the evaluation form of the training quality management (teaching staff's data)

\begin{tabular}{ccc}
\hline Choice level & Frequency & Percentage \\
\hline Level 1 & 1 & $0.15 \%$ \\
Level 2 & 21 & $3.15 \%$ \\
Level 3 & 144 & $21.59 \%$ \\
Level 4 & 370 & $55.47 \%$ \\
Level 5 & 131 & $19,64 \%$ \\
\hline
\end{tabular}


The table above shows again the frequency of teaching staff's responses, mainly focusing on level 4 (good quality), almost no one chooses levels 1, 2 (very bad, bad).

\subsection{Results of interviews with students and teaching and management staff}

The interview consists of 5 questions relating to quality assurance, the applicability of training quality management according TQM model, the difficulty of applying training quality management according to the criteria of TQM model, opinions about criteria of training quality management and ideas about the applying training quality management according to TQM model to the school's concrete situations. The interview was used to assess the concerned people's opinions of training quality management in the Accounting, Analyzing and Auditing program in the VNU International School and the following results were achieved.

\subsubsection{Students' opinions}

For the students, the number of collected opinions was relatively small, the authors selected nine students from different classes to interview. As a result, the majority of responses (7 out of 9) mentioned the insufficient understanding, experience and reality to assess the content of the interview questions.

However, there is a comment that it might be a good idea to discuss the training quality management, TQM and get opinions from students in the dialogue with the school's leaders.

Regarding the evaluation criteria, there is the opinion that as the questions cover most of the aspects, they can be applied in reality; on the contrary, there is another comment that some of the questions seem to be sketchy and unclear.

Relating to the levels of difficulty, 02 students fear that the implementation could just be some sort of formality and supported by few people. That is to say, the actual environment is different, and the application of management criteria may not be suitable for all HEI's.

\subsubsection{Teaching staff's opinions}

For staff interviews, the comments received during the interviews were both positive and positive.

When asked about the possible application of the assessment of training quality management in accordance with TQM criteria, 13 out of 23 respondents agree that the assessment of training quality management by TQM criteria is applicable, some of which are answered by stating that (i) the criteria can be applied but they should be more concretized, (ii) the language used in criteria should be simplified and more concise, (iii) they very much agree with the criteria they can be completely applicable, and (iv) it is feasible and practical to apply the TQM criteria, however, if the implementation follows a step-by-step roadmap.

Relating to the question about the difficulties in implementing the assessment of training quality management, there are different opinions and comments. Some state that in many cases, the reality of the school's human resources and physical facilities cannot meet quality standards, thus affecting the learners' general assessment of training quality management. Others hold that there should be more investment in upgrading equipment, physical facilities and implementing training quality management according to TQM model. Besides, training quality management also depends on leaders' concept and teachers' and leaners' as well as participants' awareness of the issue or students' cooperative attitude, accuracy and seriousness when conducting assessment is a major difficulty. Some think that students' feedback is not highly effective because students are not fully aware of its significance, they just follow the movement thus affecting the accuracy of feedback results. There is even an opinion that TQM awareness among staff, faculty and students is not high nor the same, and there are not enough human resources to carry out training quality management. 
In summary, the greatest difficulty would be to collect information in order to make accurate and objective judgments, followed by the difficulty in leaders', staff's and students' awareness of training quality management and finally the resource constraints to effectively implement the assessment.

The last question relates to the ideas about the applying TQM model to the school's concrete situations and the answer is that it is necessary to develop an objective, accurate and realistic written assessment of the training quality management for students, or questions should be easier to understand, or there should be more space for personal opinions and another criterion relating to the surveys of research activities and enterprise projects.

In terms of the ideas/opinions of applying the TQM model, there are some comments. For example, for implementation, the management channels should be synchronic or short-term and long-term regulations and financial mechanism for implementing training quality management should be in place or results of training quality management according to TQM should be considered as one of the criteria for raising salaries, giving bonuses or rewards to everyone in the school.

In short, it can be said that all the opinions are authentic and realistic, reflecting the real situation of the applicability of training quality management according to TQM in VNU International School.

\section{Conclusion}

This paper has primarily assessed the status of training quality management in accordance with TQM model. With a case study and the application of qualitative and quantitative methods by using questionnaire, semi- structured interview, it has drawn the three following conclusions.

Firstly, the current situation of training quality management according to TQM is considered to be at an average level, as perceived by students, the most important customers in higher education where the quality is aligned with their purpose and satisfaction. Therefore, their opinions and comments should be thoroughly considered.

Secondly, all students and staff agree that the implementation of assessment of training quality management in accordance with TQM criteria is feasible, they express their support for this assessment.

Lastly, this paper has also outlined some criteria for the development/ establishment of the evaluation tools such as sample forms, guidelines and evaluation procedures; surveys, process and analysis of results; and performed the advisory function of quality assurance in VNU International School.

\section{References}

[1] Trần Khánh Đức (2004), Quản lý và kiểm định chất lượng đào tạo nhân lực theo ISO\&TQM , Nxb Đại học Quốc Gia Hà Nội, Hà Nội.

[2] Phạm Xuân Thanh (2011). Đo lường đánh giá trong giáo dục: Mô hình Rasch trong phân tích kết quả học tập. Tài liệu giảng dạy lớp thạc sĩ đo lường đánh giá.

[3] Lâm Quang Thiệp (2011), Đo lường trong Giáo dục - Lý thuyết và ứng dụng, Nxb Đại học Quốc gia Hà Nội, Hà Nội.

[4] Sallis, E (1993), Total Quality Management in Education, London: Kogan Page.

[5] Saunder, M., Lewis, P. Thornhill, A. (2003), Research Methods for Business Students ( $\left.3^{\mathrm{rd}} \mathrm{ed}\right)$, London: FT Prentice Hall.

[6] Wikipedia, Total Quality Management, http://en.wikipedia.org/wiki/Total_quality_mana gement, cập nhật này 17.5.2013. 